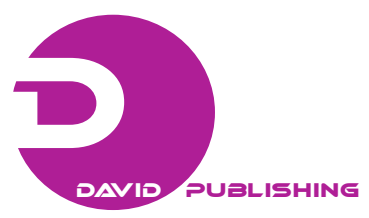

\title{
Informal Settlements: A Shape Grammar Approach
}

\author{
Maria Angela Dias \\ School of Architecture and Urbanism, Federal University of Rio de Janeiro, Rio de Janeiro 22 291-090, Brazil
}

\begin{abstract}
Informal urban development is seldomly covered in academic studies or professional architectural training. This article sets forth the first stage of a novel study that observes the informal city using the methodology of analysis of architecture called shape grammars. The idea is to recognize peculiarities in the occupation of the land and the volumetric features of the buildings. Rocinha favela, in Rio de Janeiro, Brazil, is taken as a case study with the primary aim of extrapolating a set of rules for its morphological features so that these rules can be used to generate new shapes, whilst bearing in mind the issues of adaptation and transformation which are so characteristic of informal settlements. There is some expectation that this study may help improve the housing and public space in the favela and enable new housing programs to observe the way the buildings and different architectural elements combined, forming a new channel of interchange with the spatial organization of the favela.
\end{abstract}

Key words: Shape grammar, analysis of the form, informal architecture.

\section{Introduction}

Both academic studies and professional architectural training fail to cover informal urban development. Perhaps the power of modernism, with its different categories and sectors, has left no room for the study of exceptions. Brazil's informal architecture, known collectively as the favela, incorporates elements of the national culture and can be perceived as a housing solution.

This article presents the first stage of a wider study, which is still underway, that observes the informal city by means of a shape grammar to recognize the occupation of the land and the volumetric features of the buildings.

Rocinha favela is taken as a case study with the primary aim of identifying its main morphological features under a set of rules which have the power to generate new shapes, whilst bearing in mind the issues of adaptation and transformation which are so characteristic of informal settlements. This study therefore aims to prompt reflections on the potential for

Corresponding author: Maria Angela Dias, professor, architect, research fields: education in architecture, analysis of architectural form and descriptive geometry. E-mail: magelias@uol.com.br. organizing favelas and the development of new low-income housing projects, considering the features that are typical of informal groups of buildings, which follow a different rationale from the formal city.

\section{Characteristics of Favelas}

It is a rather hard task to understand what facts and causes are instrumental in the formation of informal agglomerations. It should also be noted that although the physical form has been chosen as a criterion for inferring rules of architectural composition, this means that the fact that the favela's morphology is the outcome of socioeconomic dynamics will be take into account.

Situated between the upper-middle-class districts of São Conrado (Fig. 1) and Gávea (Fig. 2) in the city of Rio de Janeiro, Rocinha officially covers 143.72 ha [1] and has a population of almost 69,500 [2]. A district of the city is officially made in 1993.

More in-depth knowledge of the community will be produced during the analysis that is being conducted by the research group investigating the application of shape grammar to the formal and informal cities. Considering the sheer size of the favela, one area which had already been described in detail [3], including the 


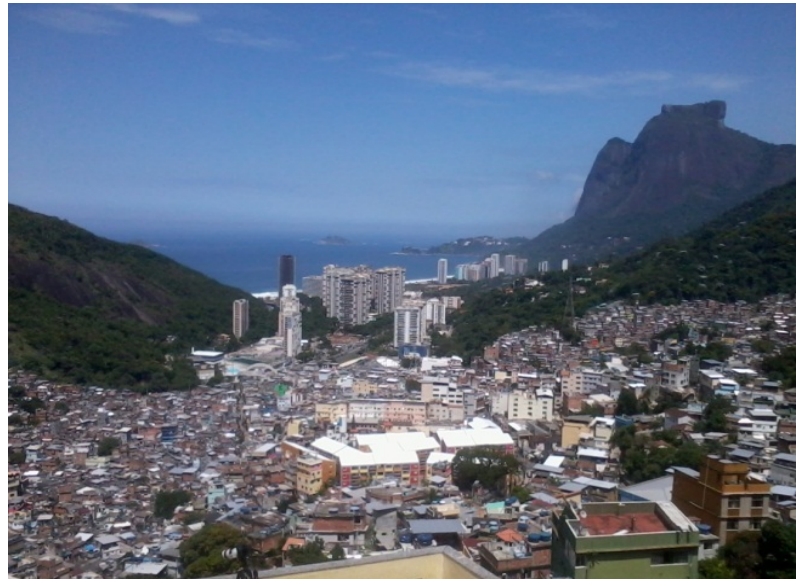

Fig. 1 District of São Conrado.

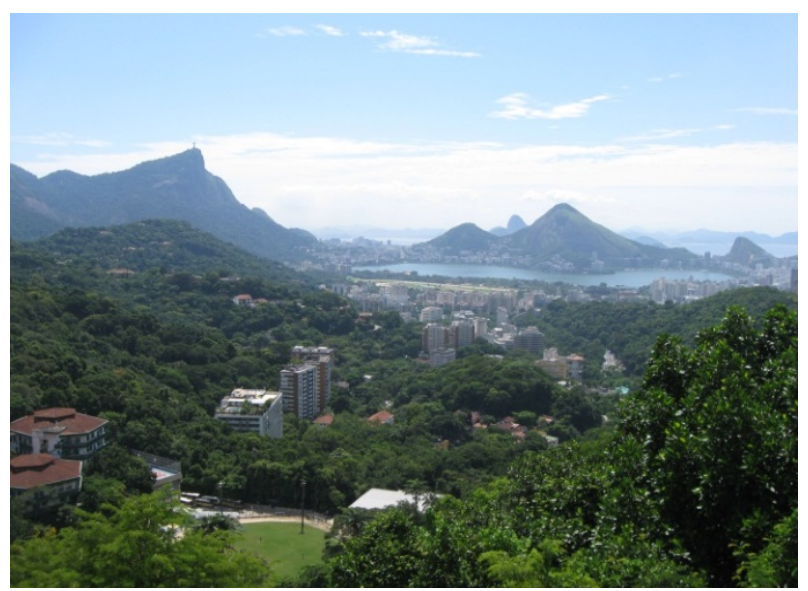

Fig. 2 Distric of Gávea.

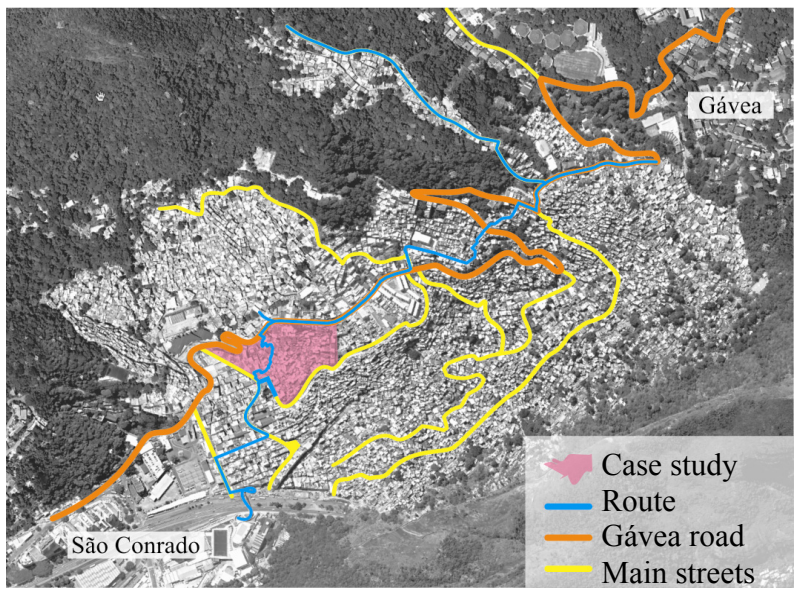

Fig. 3 Aerial view of Rocinha.

production of statistical data, was selected as a case study (Fig. 3).

On their first field trip to the favela, what the researchers found as they visited the different roads and alleys was a vast array of diversity in the arrangement of the buildings in the land, and the distribution and formats of the peripheral routes and access ways.

In order to prepare a shape grammar, some aspects of the area were observed which, together with the existing statistics and literature reviewed, enabled a first compositional language to be prepared using a shape grammar.

Below are a few examples of these items.

Rocinha is linked to other districts of the city via the Gávea road (Estrada da Gávea) and the Lagoa-Barra highway (Autoestrada Lagoa-Barra), the main road linking the south zone of Rio with the district of Barra da Tijuca.

The main circulation route in Rocinha is Estrada da Gávea. The steep gradient of the land in the favela has forced adaptations to be made involving access ways via stairs and ramps, resulting in a complex web of internal connections known as alleys.

The buildings in the favela include residential housing, banks, stores, restaurants, churches, healthcare establishments, administrative establishments, daycare centers, NGOs (non-government organizations) working in different areas, schools, etc..

This is a dense urban agglomeration with almost monolithic volumetric features, penetrated by a veritable maze of alleys and stairways (Fig. 4).

The buildings tend to extend upwards, which poses a risk to their stability (Fig. 5).

The buildings are set cheek-by-jowl, leaving little or no room for sideways expansion (Fig. 6).

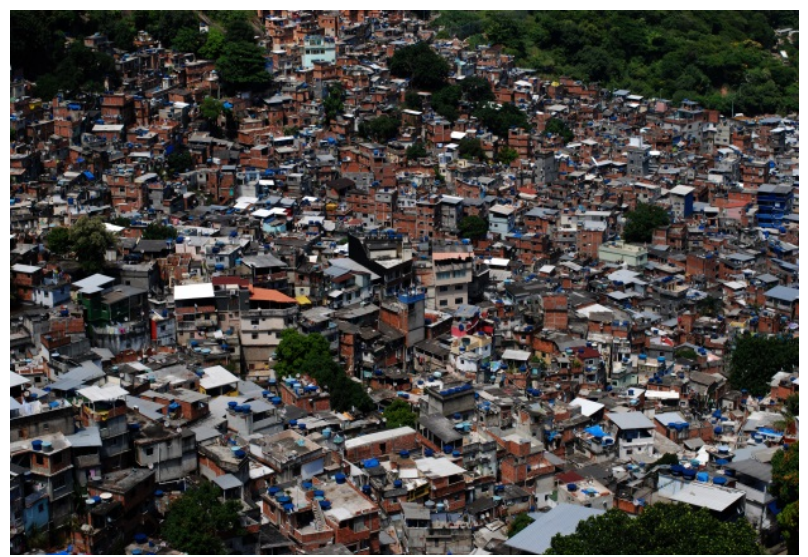

Fig. 4 Dense urban. 


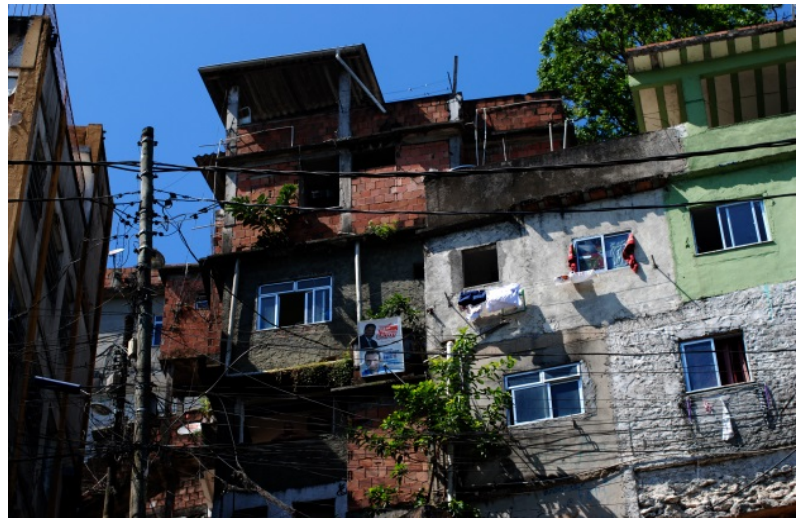

Fig. 5 Risk to stability.

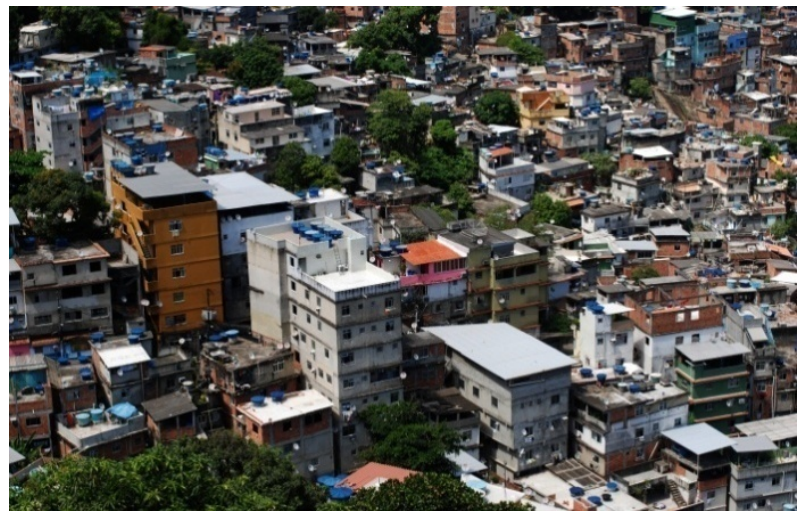

Fig. 6 Verticality.
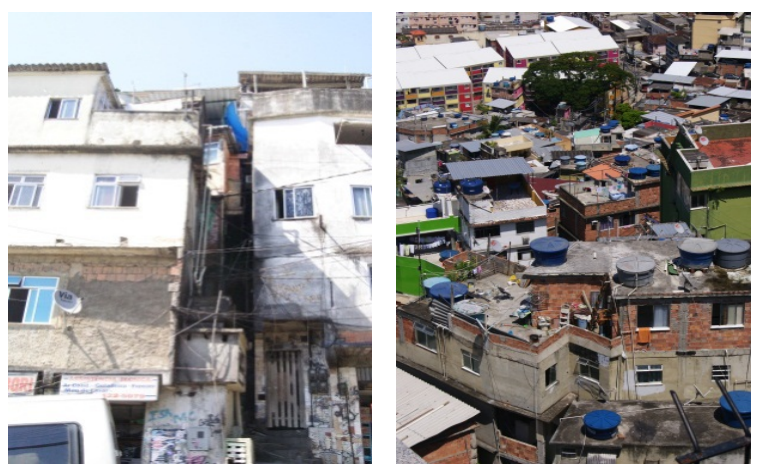

Fig. 7 In salubriousness.
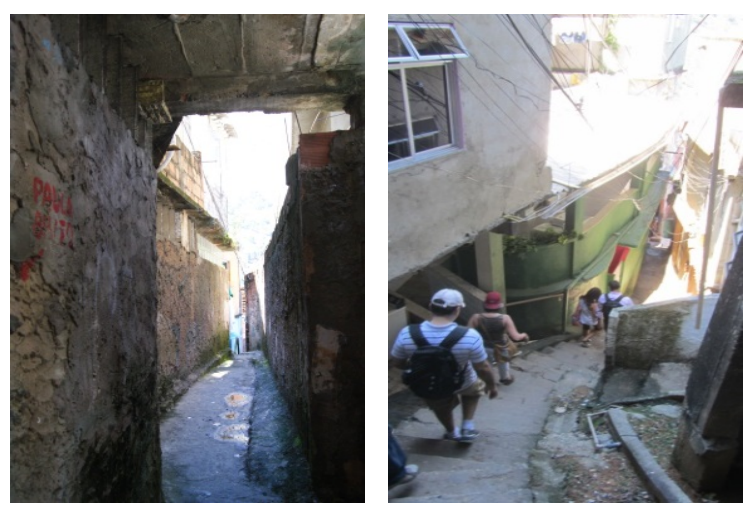

Fig. 8 Formation of tunnels/difficulty of access.
The housing generally has little or no ventilation (Fig. 7) and no direct sunlight [4].

The buildings on the more steeply sloping land are normally inhabited by more than one household and can be accessed at different levels (Fig. 8) with overhangs which end up covering some sections of the access ways, forming tunnels [1].

The residents would like to stay there to see the area urbanized and to have public services available where they live [5].

Building extensions are a source of income: the real estate market (buying, selling and renting) has its own particular rules.

The economy is dynamic and integrated into the urban growth of the rest of the city.

\section{Using Shape Grammars}

\subsection{Understanding Shape Grammars}

The shape grammar was first developed by George Stiny and James Gips in the early 1970s. It is a formalist methodology based on a number of rules that make up a system for generating shapes [6]. These rules organize knowledge about shapes by creating a language to characterize groups of buildings. This model for the creation of a design language as conceived by Stiny and Gips is based on Chomsky's [7] generative grammar.

The method consists of defining a set of basic elements such as: a vocabulary of shapes, spatial relations between the basic shapes from the vocabulary, defining the spatial relations using rules and defining the initial shape for applying the rules. Finally, the rules are applied to understand and produce designs in the original style, or else to expand the style, yielding new designs.

This methodology has important applications in the teaching of analysis and composition in architecture courses [8]. One of the best known studies applying a shape grammar to the field of architecture was that of Palladio's villas [9]. This was followed by important articles on different buildings, such as Frank Lloyd Wright's prairie houses [10], Japanese tea houses [11] 
and the houses in Malagueira by Álvaro Siza Vieira [12].

Later, "The Logic of Architecture" [13] presented a computational dimension for shape grammars as a process for logical operations in the design process. Most studies using shape grammars are analytical applications which consist of choosing a group of buildings with elements which appear to have some similarities between them [14].

One of the best-known analyses of urban areas using shape grammars is the research of the Zaouiat Lakhdar quarter of the Medina of Marrakech [15]. With an urban scale, this analysis describes the layout of the roads, the scale of the architecture and the way the buildings organized. For each analysis scale, different rules were derived and parameters were used to generate the rules.

The analysis of Rocinha, in Rio de Janeiro, will be based on these aforementioned studies, especially the procedure adopted in the Marrakech study. This first analysis stage was conducted during a workshop held at the Federal University of Rio de Janeiro under the supervision of Terry Knight (MIT (Massachusetts Institute of Technology)) and Gabriela Celani (University of Campinas), marking the beginning of an ongoing and in-depth investigation of the rules of occupation of the Rocinha community, its origins and development.

\subsection{A Shape Grammar for Settlement Patterns}

The organization of land use and occupation in Rocinha is a key issue for assuring better living conditions for its residents. Its formal layout is the result, in the main, of its topography, which makes the housing conditions more precarious and also restricts circulation and access. Estrada da Gávea is an important road as the favela space is organized around it with smaller roads, alleys and stairways leading off it.

In recognition of the peculiarity of its structure, a distinction was drawn between the building of houses along the official road network, made up of the main roads and/or roads that existed before the favela, and buildings inside the area demarcated by them. That observation was made before the rules for the settlement of buildings were defined.

While the former category of housing is more structured and organized, the latter is organic and spontaneous, resulting in a very intricate design that forms a veritable labyrinth. For this reason, one set of rules was prepared for the housing along the main roads and another for the housing that spreads inwards from them [16].

In the rules for the layout of buildings along the main roads, a maximum number of contiguous buildings has been identified before an alley appears. There is also a rule that allows buildings to be built behind the buildings along the main roads (Fig. 9).

Considering the natural movements of people between points of interest in the community on different roads, we have defined rules for the creation of routes connecting pre-existing roads. In these rules, we take into account the contours of the terrain, which in turn determines how straight or winding the routes are, or whether they are stairways with their uneven steps (Fig. 10).

For housing accessed by alleys, there is no restriction on the number of contiguous buildings. Also, each new house may spawn a new access way or even block an existing one (Fig. 11).

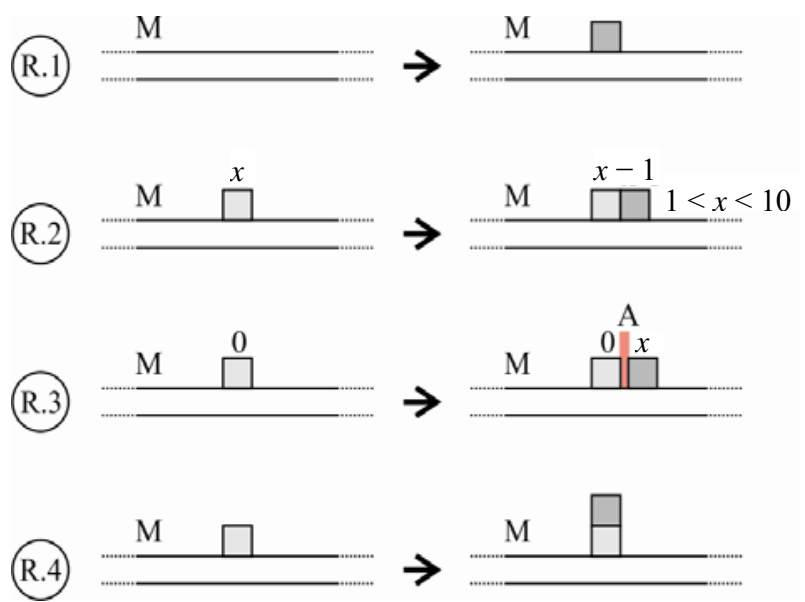

Fig. 9 Rules for main streets. 
(R.5)

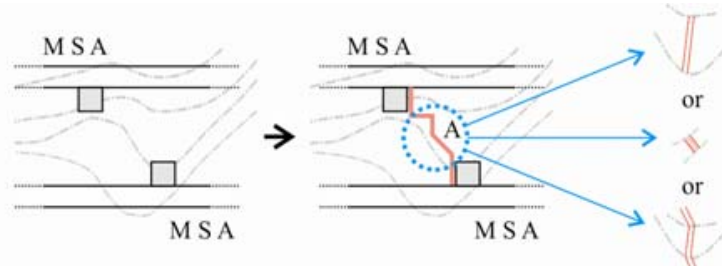

Fig. 10 Rules for connecting streets or allies.

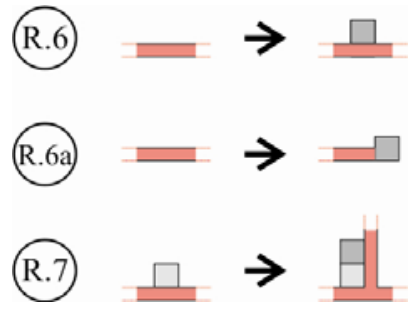

Fig. 11 Rules for allies.

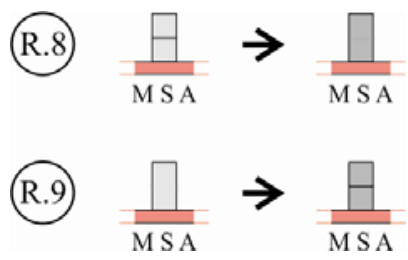

Fig. 12 Rules for the extension and division of buildings.
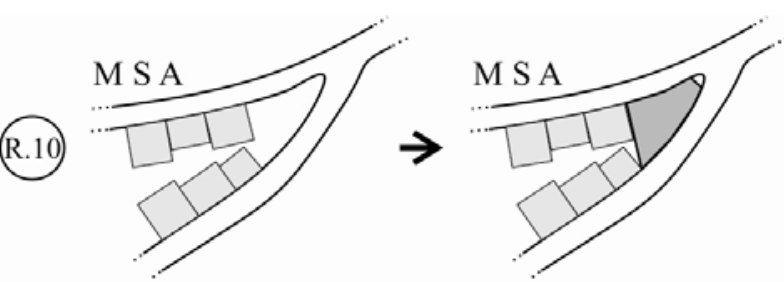

R.11
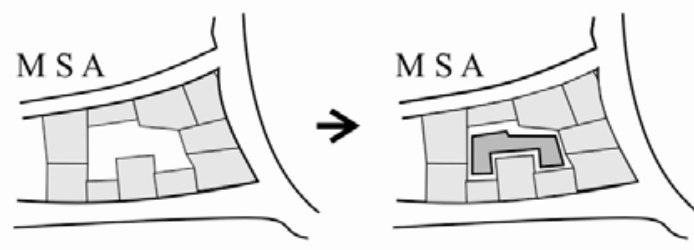

R.12
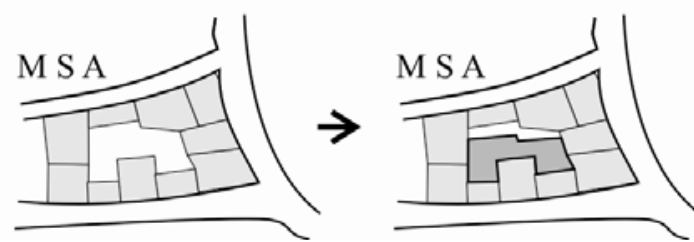

Fig. 13 Rules for filling empty spaces.

Finally, alongside the rules for the organization of the settlement, rules have also been determined for the extension and internal division of buildings (Fig. 12) and for the filling of empty spaces, i.e., the unoccupied areas on which houses are built, with uneven shapes (Fig. 13).

\subsection{A Shape Grammar for Buildings}

As already mentioned, the topography has an impact on the layout of the buildings, which are scaled according to the gradient of the slope, generally respecting the existing contours and involving little in the way of earthworks or slope erosion control. These buildings, which are home to more than one household and can be accessed at different levels, have overhangs that cover up some sections of the access ways, forming tunnels. The volumes of these groups of buildings and the way the houses are organized internally will be addressed in the second stage of the research project.

In this first stage of the study, rules have been inferred for buildings by the observation of the external features that tend to recur in most of the houses and the frequency with which these elements are repeated. As such, the vocabulary includes exposed slabs, walls, balconies, covered exposed slabs and water tanks (Fig. 14). The spatial relations are the ways in which one element may be combined with another, and the rules defining when and how these spatial relations take place [16].

In order to characterize the figures, a color grammar [17] was adopted, which consists of assigning colors to the elements from the vocabulary. Green is for the plot of land, which is the initial shape. Blue is used for exposed slabs, which have the same shape as the plots of land. This distinction is important when the rules are applied, because when shapes are identical, distinctions must be made when applying the rules to one element or another.

Likewise, colors are also used for the facades in order to differentiate front facades (red) from sides (yellow). This also comes into play when the rules are applied to the composition of the facades.

The tree diagram demonstrates the capacity for variation provided by the rules, in keeping with the 
R.1)

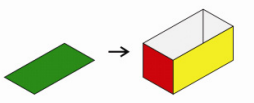

(R.6)

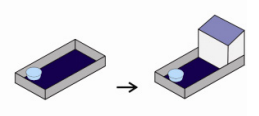

(R.2)

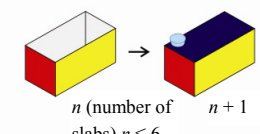

(R.7)

(R.3)

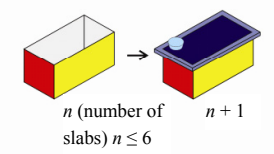

(R.4)

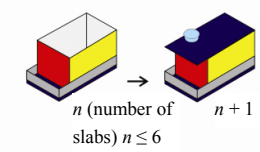

(R.5)

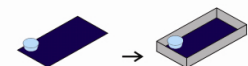

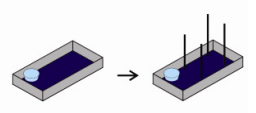

(R.8)

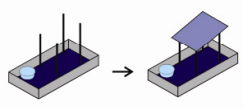

(R.9)

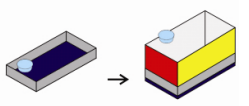

R.10)

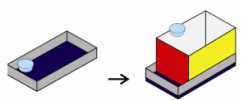

Fig. 14 Rules for building composition.

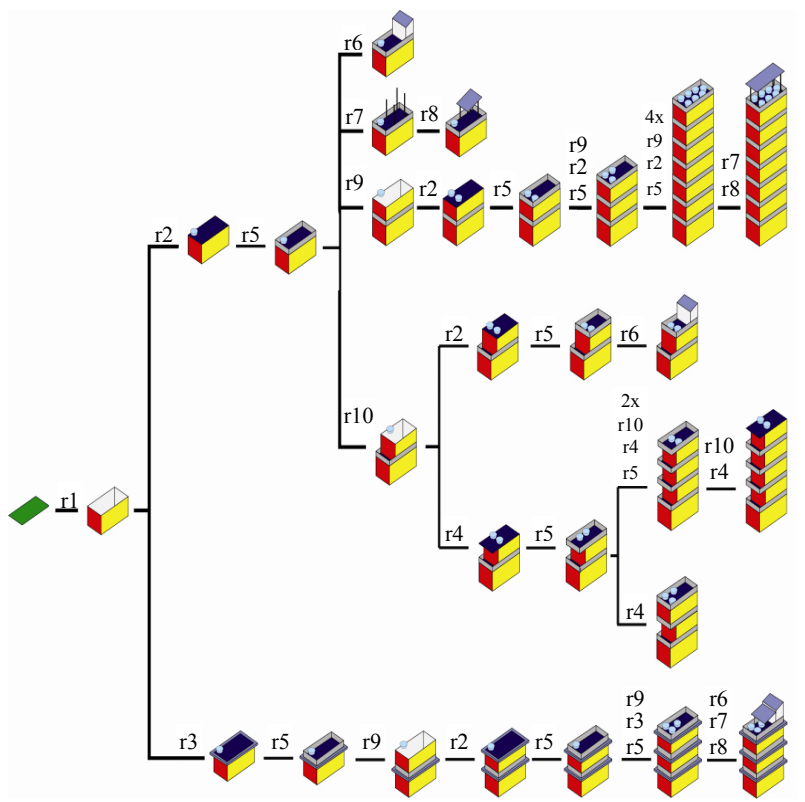

Fig. 15 Tree diagram with the possible application of the rules.

analysis requirements, even if not all the potential options are covered (Fig. 15). The rules may be applied more than once, provided the precondition for applying the rule is met. As such, parameters must be set to define the maximum number of repetitions [16].

The computational implementation of the rules is one of the key stages in the analysis process. In fact, the word "computation" does not necessarily mean using a computer, but rather the logic of applying the rules, which is also a way of identifying problems in the process, such as faults that may occur when the rules are applied as well as errors or redundancies, for instance. In this phase, the grammar can also be corrected and refined. In the first computation, the color grammar was used to resolve problems of ambiguity. At the next stage, the redundant rules were removed and other rules were improved by including new elements.

It is important to stress that this is an abstract representation of the buildings, so the order in which the rules are applied does not necessarily correspond to the chronological order of the real events: they are the outcome of the observation of the relationships between the elements and the best way of optimizing the rules. Another important consideration is that there are no definitive grammars, since they depend on the set of vocabulary and rules adopted.

\section{Conclusions}

Rocinha favela, today known as Rocinha community, encompasses a multiplicity of interests and a diversity of social circumstances. However, its spatial features contain elements of Brazilian popular architecture which could be incorporated into low-income housing projects. Recognizing the peculiarity of its spatial structure therefore seems to be a valid first step for devising ways to improve this built environment, which has taken shape according to a rationale that differs from the concepts that underpin the structure of the official city.

This approach to the analysis of the Rocinha urban area is innovative. As far as the authors are aware, no other studies in Brazil have used shape grammars to analyze the Rio de Janeiro favela, for which very reason, there is some expectation that this study may help improve the housing and public space in the favela and enable new housing programs to observe the way the buildings and different architectural elements combined, 
forming a new channel of interchange with the spatial organization of the favela. The intention of the work is to infer rules that reflect the coordination between the different elements that make up the informal architecture in a unique pattern of urban development.

\section{Acknowledgments}

The author would like to thank everyone who took part in the analysis of Rocinha favela in a shape grammar workshop as part of the research project, "Teaching Observation: Apprehending the Geometric Attributes of the Shape of Places". I particularly want to thank the contributions made by doctoral students Danusa C. Gani, Gustavo Pimenta, Margaret L. Chokyu and Lilian Soares; master's students Alberto Fernandes, Claudia Elias and Luciano Monteiro; architects Veronica Natividade and Marat Menezes; and undergraduate research grant holder Pedro Valcarce.

\section{References}

[1] J.S. Farias, The shape of informality: An analysis of urban morphology of Rocinha, Rio de Janeiro, Master's Dissertation, Federal University of Rio de Janeiro, Graduate Program in Urbanism, 2009.

[2] IBGE (Brazilian Institute of Geography and Statistics) [Online], 2010, http://www.ibge.gov.br/home/estatistica/ populacao/censo2010/ (accessed Nov. 20, 2013).

[3] Public National Ideas Competition for the Redevelopment Complex Favela Rocinha, Mayerhofer e Toledo Architecture Planning Consulting Ltd., 2006.

[4] G. Leitão, Challenges of Urbanization in Large Slums Process: The Case of Rocinha, the City of Rio de Janeiro [Online], http://www.usp.br/nutau/CD/116.pdf (accessed Aug. 22, 2013).

[5] L.P. Valladares, A invenção da favela: do mito de origem a favela.com (The Invention of Favela-The Myth of Rigin
Favela.com, Rio de Janeiro), Editora FGV (Getulio Vargas Foundation), Rio de Janeiro, 2005. (in Portuguese)

[6] G. Stiny, J. Gips, Shape grammars and the generative specification of painting and sculpture, in: Proceedings of Information Proceedings 71 [Online], pp. 1460-1465, http://www.shapegrammar.org/ifipq.html (accessed Aug. 30, 2013).

[7] N. Chomsky, Syntactic Structures, Mouton, The Hague, 1957.

[8] T. Knight, Application in Architectural Design, and Education and Practice, Report for the NSF (National Science Foundation)/MIT (Massachusetts Institute of Technology) Workshop on Shape Computation, 1999.

[9] G. Stiny, W.J. Mitchell, The Palladian grammar, Environment and Planning B 5 (1978) 5-18.

[10] H. Koning, J. Eizenberg, The language of the prairie: Frank Lloyd Wright's prairie houses, Environment and Planning B 8 (1981) 295-321.

[11] T.W. Knight, The forty-one steps, Environment and Planning B 8 (1981) 97-114.

[12] J. Duarte, Towards the mass customization of housing: The grammar of Siza's houses at Malagueira, Environment and Planning B: Planning and Design 32 (3) (2005) 347-380.

[13] J.W. Mitchell, The Logic of Architecture, T.G. Celani (Ed.), Editora Unicamp, Campinas, 2008.

[14] G. Celani, A Gramática da Forma como metodologia de análise e Síntese em arquitetura (Grammar form and analysis methodology and synthesis in architecture), Conexão-Comunicação $\quad$ e $\quad$ Cultura (Connection-Communication and Culture) 5 (10) (2006) 191. (in Portuguese)

[15] J.P. Duarte, G. Ducla-Soares, L.G. Caldas, J. Rocha, Unveiling the structure of the Marrakech Medina: A Shape grammar and an interpreter for generating urban form, Artificial Intelligence for Engineering Design, Analysis and Manufacturing 21 (4) (2007) 317-349.

[16] M.A. Dias, D.C. Gani, M.L. Chokyo, The logic of favela by shape grammar, in: Proceedings of the 2nd International Seminar on Representation, 2013, p. 23.

[17] T.W. Knight, Color grammars: The representation of form and color design, Leonardo 26 (1993) 117-174. 